\title{
Fragmentação Florestal Em Área De Mata Atlântica No Sul Do Brasil: Uma Análise Baseada Em Métricas Da Paisagem
}

\author{
Structural Forest Fragmentation In An Area Of Atlantic Forest In South Of \\ Brazil: Analysis Based On Landscape Metrics
}

Cristiane Scussel', Jairo José Zocche ", Nilzo Ivo Ladwig "', , Danrlei De Conto IV

RESUMO

Este estudo analisou a estrutura da paisagem de duas microbacias hidrográficas contíguas, localizadas na região sul do estado de Santa Catarina, Brasil, no intuito de avaliar o cenário da fragmentação estrutural florestal à época do imageamento. Foi utilizada imagem fotogramétrica ortorretificada, escala de 1:10000, datada de 2011 para a identificação das classes cobertura e uso da terra e para a produção de mapas temáticos em ambiente SIG, que se deu com auxílio do software ArcGis versão 10.3.1. A opção pelo ano de 2011 para estudo se deu pela disponibilidade de imagens mais recentes, com resolução espacial adequada às necessidades requeridas pela análise. Os arquivos vetoriais dos mapas temáticos produzidos foram importados no software Fragstats versão 4.2, que gerou o relatório das métricas da paisagem. Foram identificadas seis classes de cobertura e uso da terra que juntas somaram 649 fragmentos distribuídos em 4453,9 ha. Os fragmentos florestais ocuparam $45 \%$ da área total mapeada, cerca de $90 \%$ deles tinham área menor do que 6,45 ha e apresentaram índice de forma média igual a 2,2, o que evidencia bordas altamente recortadas. A distribuição espacial destes fragmentos, indicava alto grau de conectividade estrutural e embora grande parte da área estivesse ocupada por formações florestais, a perda de habitats originais da Floresta Ombrófila Densa Submontana resultante das ações antrópicas foi maior do que $50 \%$, o que sugere que em se tratando de conservação de habitats, tanto os fragmentos maiores quanto os menores em conjunto devem ser motivo de conservação.

Palavras-chave. Floresta Ombrófila Densa, Perda de habitat, Conectividade estrutural

\section{ABSTRACT}

This study aimed to analyze the landscape structure of two contiguous river basins, located in the southern of Santa Catarina state, south Brazil, in order to evaluate the scenario of structural forest fragmentation at the time of imaging. We used an orthorectified photogrammetric image, scale of 1: 10000, dated from 2011, for the vectorization of use and land cover and to production of thematic maps, using the ArcGis software version 10.3.1. The choice by the year 2011 for study was due to the availability of more recent images, with spatial

Mestre pelo Programa de Pós Graduação em Ciências Ambientais na Universidade do Extremo Sul Catarinense. E-mail. cris. scussel@hotmail.com ORCID: http://orcid.org/0000-0003-0242-5566

" Professor do Programa de Pós Graduação em Ciências Ambientais na Universidade do Extremo Sul Catarinense .E-mail.jjz@unesc.net ORCID https://orcid.org/0000-0003-2291-3065

III Professor do Programa de Pós Graduação em Ciências Ambientais na Universidade do Extremo Sul Catarinense. E-mail ladwig@unesc.net. ORCID https://orcid.org/0000-0003-3031-0192

Iv Mestrando pelo Programa de Pós Graduação em Ciências Ambientais na Universidade do Extremo Sul Catarinense. E-mail. danrleideconto@hotmail.com ORCID https://orcid.org/0000-0002-1256-4263 
resolution adequate to the needs required by the analysis. The thematic maps produced were imported in the software Fragstats version 4.2, which generated the report of the metrics of the landscape. Six classes of cover and land use have been identified, which together totaled 649 fragments distributed over 4453.9 ha. The forest fragments occupied $45 \%$ of the total mapped area and about $90 \%$ of them had an area smaller than 6.45 ha. The average index of forest fragments was 2.2, which shows highly cut edges. The spatial distribution of these fragments indicates a high degree of structural connectivity. Although great part of the area of the basins was occupied at the time of imaging, by forest formations and the structural connectivity was high, the loss of forest habitats was greater than $50 \%$, which suggests that in the sense of conservation, both the largest and the smallest fragments together must be reason for conservation.

Keywords: Dense Ombrophilous Forest, Habitat loss, Structural connectivity

\section{INTRODUÇÃO}

A paisagem pode ser interpretada como uma unidade espacial, resultante de fenômenos naturais ou antrópicos que nela ocorrem (MORAES, 2015). Em seu estudo, que é objeto de uma ciência emergente, a Ecologia de Paisagem (FORMAN; GODRON, 1986; METZGER, 2001; FORNECK; PORTO, 2008), devem ser analisados a estrutura, a função e a dinâmica (FORMAN; GODRON, 1986; TURNER, 1991; NAVEH; LIEBERMAN, 1994), bem como, seus efeitos sobre distribuição e a abundância dos organismos (FAHRIG, 2005). A Ecologia de Paisagem está fundamentada na premissa de que os padrões de composição e de distribuição das manchas de habitat na paisagem influenciam fortemente os processos ecológicos (MCGARIGAL; MARKS, 1995).

A perda de habitat pode levar a fragmentação da paisagem (METZGER, 2013). Esta ocorre quando uma grande extensão de habitat é transformada em um número maior de manchas com menor tamanho, isolando-as umas das outras por uma matriz de habitat diferente do original (WILCOVE; MCLELLAN; DOBSON, 1986; FORMAN, 1995; JACKSON; FAHRIG, 2013). A fragmentação de habitat pode se dar por causas naturais e antrópicas (CONSTANTINO, 2003; LANG; BLASCHKE, 2009) e os seus efeitos sobre a estrutura da paisagem podem ser negativos, uma vez que altera a diversidade e a composição das comunidades (LAURANCE; VASCONCELOS, 2009), mas também podem ser positivos, quando o isolamento das manchas não atinge um determinado limiar, pois, aumenta a diversidade de habitats, incrementa a conectividade funcional e torna as bordas mais produtivas e mais diversas (FAHRIG, 2017a).

Para entender melhor os efeitos da fragmentação sobre as populações em regiões com alta redução de habitat nativo, foi proposto um limiar de fragmentação (ANDRÉN, 1994; FAHRIG, 2003). Este limiar varia entre 20 e $30 \%$, sendo que acima de $30 \%$ os efeitos atuariam sobre a redução populacional e sobre a perda da biodiversidade e, abaixo desses valores seriam somados aos da 
distribuição espacial dos fragmentos que tenderiam ao isolamento. Esses efeitos podem afetar diretamente a fauna, conforme detectado em estudos empíricos (p. ex.: PARDINI et al., 2010; OCHOAQUINTERO et al., 2015). No entanto, um dado limiar pode variar conforme a suscetibilidade de cada grupo de organismo (LINDENMAYER; LUCK, 2005).

No processo de fragmentação, o tamanho e a forma dos fragmentos resultantes diferem do habitat original em razão da alta relação borda/área e pelo fato de o centro de cada fragmento ficar mais próximo à borda (CERQUEIRA, 2003). Outros parâmetros estruturais da paisagem que tem influência sobre os organismos que a exploram são o grau de isolamento e a conectividade funcional entre as manchas. A conectividade é aqui definida como a capacidade de uma dada paisagem de facilitar a movimentação de indivíduos entre manchas de habitat (TAYLOR, 1993).

Uma das formas mais utilizadas para analisar o grau de fragmentação de uma paisagem e sua influência sobre os processos ecológicos é o cálculo de métricas da paisagem (MCGARIGAL; MARKS; 1995; METZGER, 2012). As métricas representam medidas quantitativas de composição de uma paisagem e podem ser agrupadas em várias categorias, podendo ser analisadas em três níveis fundamentais: de mancha, de classe e de paisagem (MCGARIGAL; MARKS, 1995; LANG; BLASCHKE, 2009; METZGER, 2012). Podem ainda, de acordo com Metzger (2012) ser agrupadas em métricas de composição (riqueza de unidades) e de disposição (número de fragmentos, bordas, distância do fragmento mais próximo, isolamento ao fragmento fonte mais próximo e conexão).

A fragmentação da cobertura florestal no sul de Santa Catarina vem ocorrendo desde a Colonização Europeia, que teve início em meados de 1800 (PIAZZA; HÜBENER, 1983). Intensificouse a partir de meados do século XIX com a implantação da mineração do carvão (BELOLLI; QUADROS; GUIDI, 2002), ganhando notoriedade a partir do final da II Guerra Mundial, com o desenvolvimento da mineração do carvão e com o advento das novas práticas agrícolas adotadas a partir dos anos 1970 (MARCON, 2014). Desde 1997 o sul catarinense apresenta um dos panoramas com menor cobertura vegetal florestal do Estado (IBGE, 1997). A vegetação nativa nesta região, na sua maioria representada pela Floresta Ombrófila Densa, está associada ao uso do solo para a agricultura familiar, às atividades agropastoris, à ocupação urbana (SANTA CATARINA, 1997) e à exploração da madeira (SCHEIBE et al., 2010). Boa parte dos remanescentes florestais presentes se encontram fragilizados trazendo como consequência o aumento no risco de extinção local (VIBRANS, 2013).

Os reflorestamentos com espécies exóticas quando implantados em pequenas talhões, ou os cultivos agrícolas como por exemplo, plantações de banana e café quando dispersos em paisagens florestais cumprem a função de conectar fragmentos naturais, aumentando a conectividade 
funcional para diversos grupos animais (LIMA, 2008; GABRIEL, 2013). Sabe-se que as florestas plantadas possuem diferenças na composição e na estrutura que devem ser observadas, porém, quando são ecologicamente manejadas contribuem para a conservação da biodiversidade, uma vez que possibilitam a dispersão de sementes e a movimentação de artrópodes e vertebrados (FONSECA et al., 2009).

Vários estudos foram realizados com intuito de analisar a influência das florestas plantadas sobre diferentes populações animais (p. ex.: LIMA, 2008; GABRIEL, 2013; FONSECA; DIEHL, 2004) e o cenário acima descrito coincide com a realidade da área do presente estudo, as microbacias hidrográficas do rio Carvão e do rio América, que drenam parte do município de Urussanga, no sul de Santa Catarina. Neste estudo optamos pelo termo microbacia seguindo o conceito de Rocha e Kurtz (2001) que determinam que as microbacias têm dimensões menores que 20.000 ha. A intenção de analisar em conjunto os espaços constituídos de florestas secundárias e os de silvicultura reside no fato de que a silvicultura auxilia, de alguma maneira, na conservação biológica, principalmente quando a paisagem apresenta redução dos remanescentes florestais. Outro motivo que despertou o interesse pela avaliação da influência da silvicultura na conectividade estrutural da paisagem é a importância destacada em diversos estudos que analisaram essa temática em paisagens de Mata Atlântica.

Apesar da reconhecida importância das duas microbacias estudadas, uma vez que servem como manancial de abastecimento à população humana, não há registros de estudos científicos avaliando o estado da fragmentação das mesmas. E, uma vez que as mudanças provocadas em uma paisagem afetam a biodiversidade, justifica-se a análise do seu grau de fragmentação e da heterogeneidade (FORMAN, 1995; METZGER, 1999; MORAES et al., 2015). As características estruturais de uma paisagem podem ser observadas, descritas e quantificadas, basta conhecer e compreender os caminhos que levaram às mudanças (LANG; BLASCHKE, 2009). Tais características refletem o cenário de determinado momento e, portanto, estão atreladas a data do imageamento per se. Os processos ali desenvolvidos e os padrões deles gerados representam, portanto, um recorte pontual daquele momento. Diante do exposto, o estudo teve por objetivo analisar a estrutura da paisagem de duas microbacias, cobertas originalmente pela Floresta Ombrófila Densa, no sul de Santa Catarina, no intuito de avaliar o cenário da fragmentação florestal à época do imageamento. 


\section{MATERIAL E MÉTODOS}

\subsection{Caracterização da área de estudo}

O estudo foi desenvolvido na área de abrangência das microbacias do rio Carvão e do rio América, integrantes da Bacia Hidrográfica do rio Urussanga (BHRU), município de Urussanga, sul do estado de Santa Catarina. As microbacias estão localizadas entre as coordenadas geográficas $28^{\circ} 27^{\prime} 40,17^{\prime \prime}$ - 28 $31^{\circ} 46,85^{\prime \prime}$ latitude sul e $49^{\circ} 24^{\prime} 52,35^{\prime \prime}$ 49¹8'52,95" longitude oeste de Greenwich, compreendendo 4.453,9 ha de área. Drenam em conjunto $44,54 \mathrm{~km}^{2}$ totalizando $70,01 \mathrm{~km}$ de perímetro (Figura 1). 
Figura 1 - Localização da área de estudo no município de Urussanga, extremo sul do Estado de Santa Catarina, sul do Brasil
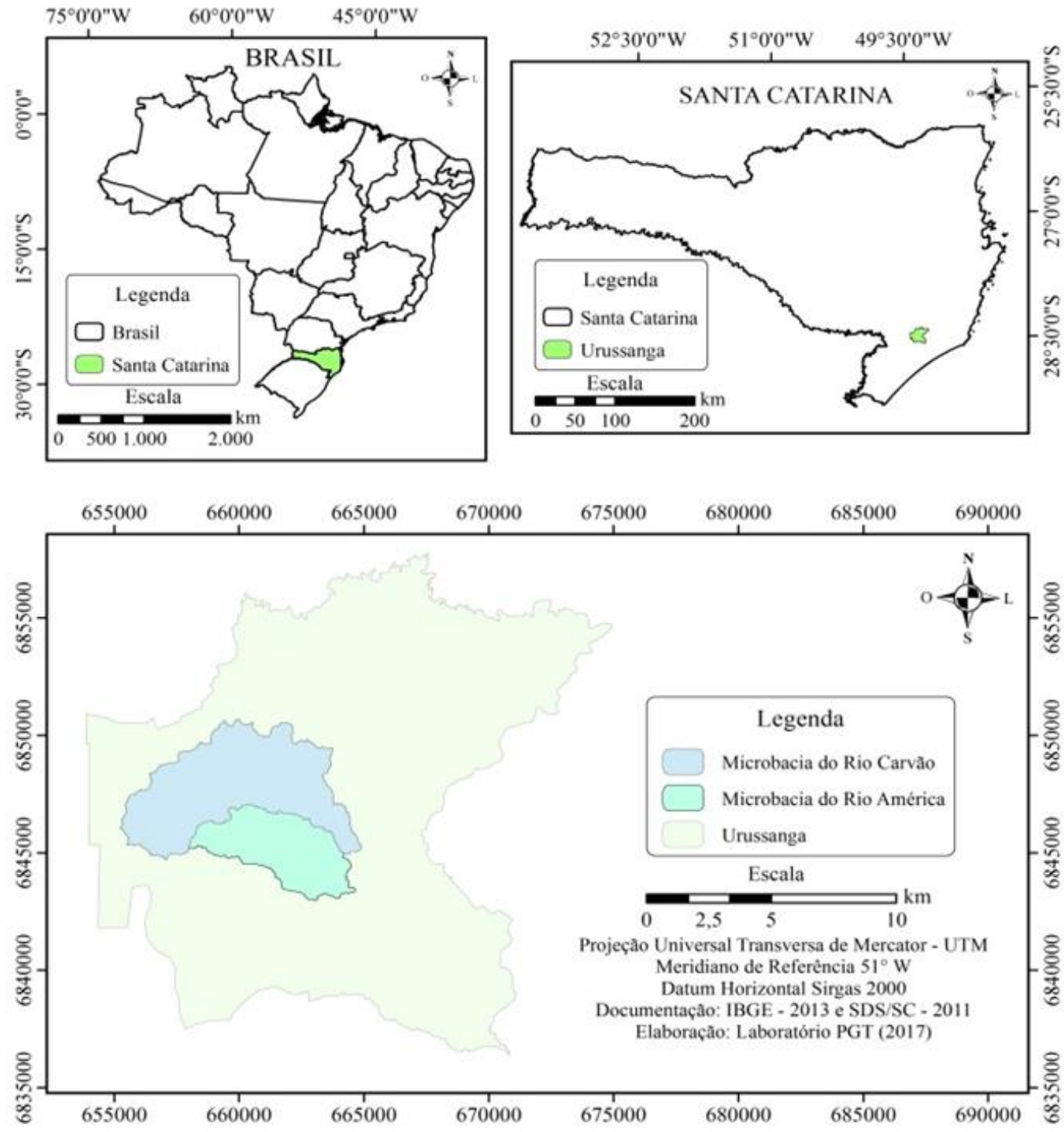

Fonte: organização dos autores

O clima da região é do tipo Cfa, caracterizado por verão quente, sem estação seca definida, com precipitação total anual variando de 1.300 a $1.600 \mathrm{~mm}$ e com chuvas distribuídas ao longo de todo o ano (ALVARES et al., 2014). O território das microbacias está inserido na Unidade Geomorfológica Depressão da Zona Carbonífera Catarinense, o relevo é do tipo colinoso (EPAGRI, 2001) e predominam os solos das classes Podzólico VermelhoAmarelo (variação PVa6) e Cambissolo (variação Ca14) (EPAGRI, 2001; EMBRAPA, 2004). A 
cobertura vegetal é tipicamente representada pela Floresta Ombrófila Densa (IBGE, 2012), que atualmente encontra-se em diferentes estágios de regeneração.

\subsection{Métodos de obtenção e análise de dados}

A paisagem foi analisada a partir da classificação das formas de cobertura e uso da terra com base em imagem fotogramétrica, datada de 2011, ortorretificada, composição $R G B$, resolução espacial de 0,39 m e modelo digital na escala 1:10.000, disponibilizada pela Secretaria de Estado do Desenvolvimento Econômico e Sustentável de Santa Catarina (SDS). Foi optado pelo ano de 2011 para o estudo, pois é a data mais próxima que disponibiliza imagens ortorretificadas com a resolução espacial adequada às necessidades requeridas pela análise.

Sobre a imagem RGB foram lançados os limites das duas microbacias, de modo a formar um único polígono. O mapeamento ocorreu a partir dos seguintes passos: 1 Interpretação visual e vetorização manual em tela de computador, com uso do software ArcGis versão 10.3.1, dos polígonos de manchas homogêneas. A individualização dos polígonos ocorreu com base em elementos de reconhecimento das manchas como: tonalidade/cor, textura, tamanho, forma, sombra e localização (FLORENZANO, 2002); 2 Classificação e atribuição de identificador (ID) às formas de cobertura e uso da terra (Tabela 1); 3 - Sobreposição do mapa de distribuição das massas d’água presentes nos limites da paisagem estudada, fornecido pela SDS (2011); 4 - Extração de dados numéricos sobre a área total ocupada pelo polígono formado pelas duas microbacias e pelas classes de cobertura e uso da terra mapeadas e; 5 - Produção de mapas temáticos da cobertura e uso da terra e da distribuição da classe de interesse (Manchas Florestais) na paisagem estudada.

A denominação das classes e descrição das formas de cobertura e uso da terra que as compõem, adotadas para o mapeamento das duas microbacias foram: Antrópica (construções civis, estradas e solo exposto em áreas mineradas não recuperadas); Agroecossistemas (cultivos agrícolas anuais); Pastagem (campo antrópico, cobertura vegetal herbácea em áreas mineradas em processo de recuperação e vegetação herbáceo-arbustiva 
espontânea sobre rejeitos de mineração); Silvicultura (plantios de Eucalyptus spp., Pinus spp. e cultivos de Musa paradisiaca); Manchas Florestais (cobertura florestal secundária em diversos estágios de regeneração - incluindo desde o estrato arbustivo até o arbóreo); e, Massas D’Água (reservatórios de água artificiais).

Os arquivos dos mapas temáticos foram convertidos a um formato raster (GeoTIFF) e submetidos às rotinas do software Fragstats versão 4.2 (MCGARIGAL; CUSHMAN; ENE, 2012) para a extração das métricas em nível de mancha, de classe e de paisagem. A estrutura da paisagem foi avaliada segundo as proposições de Metzger (2012) e teve por base a análise de métricas de composição e de disposição de elementos constituintes na paisagem (Quadro 1).

Quadro 1 - Métricas utilizadas para a análise da estrutura da paisagem das microbacias do rio Carvão e do rio América e seus respectivos significados

\begin{tabular}{|c|c|c|}
\hline Métricas & Caracterização & Justificativa da Aplicação \\
\hline \multicolumn{3}{|l|}{ Composição } \\
\hline PR (Patch Richness) & $\begin{array}{l}\text { Riqueza de classes na paisagem em } \\
\text { estudo (NP } \geq 1 \text {-adimensional). }\end{array}$ & \multirow{4}{*}{$\begin{array}{l}\text { As espécies dependem do } \\
\text { grau de heterogeneidade e } \\
\text { das dimensões das } \\
\text { manchas que compõem a } \\
\text { paisagem. }\end{array}$} \\
\hline TA (Total Area) & $\begin{array}{l}\text { Área total da paisagem analisada (em } \\
\text { ha). }\end{array}$ & \\
\hline CA (Class Area) & $\begin{array}{l}\text { Área total de cada classe na } \\
\text { paisagem }(\mathrm{em} \mathrm{ha}) .\end{array}$ & \\
\hline AREA_MN & $\begin{array}{l}\text { Área média das manchas de cada } \\
\text { classe (em ha). }\end{array}$ & \\
\hline LPI (Largest Patch Index) & $\begin{array}{l}\text { Percentual da paisagem ocupada } \\
\text { pela maior mancha da classe de } \\
\text { interesse (em \%). }\end{array}$ & $\begin{array}{l}\text { As maiores manchas podem } \\
\text { servir como áreas-fonte de } \\
\text { espécies. }\end{array}$ \\
\hline \multicolumn{3}{|l|}{ Disposição } \\
\hline NP (Number of Patches) & $\begin{array}{l}\text { Número de manchas existentes em } \\
\text { cada classe (NP } \geq 1 \text {-adimensional). }\end{array}$ & $\begin{array}{l}\text { Valores maiores indicam } \\
\text { maior fragmentação. }\end{array}$ \\
\hline $\begin{array}{l}\text { SHAPE_MN } \quad \text { (Shape } \\
\text { Index Mean) }\end{array}$ & $\begin{array}{l}\text { Índice de forma média das manchas } \\
\text { da classe de interesse (SHAPE } \geq 1 \text { - } \\
\text { adimensional). }\end{array}$ & Analisar os efeitos de borda. \\
\hline
\end{tabular}




\begin{tabular}{|c|c|c|c|c|}
\hline TCA (Total Core Area) & $\begin{array}{l}\text { Área-núcleo total da classe de } \\
\text { interesse (em ha). }\end{array}$ & & & \\
\hline $\begin{array}{l}\text { CORE_MN (Core Area } \\
\text { Mean) }\end{array}$ & $\begin{array}{l}\text { Área-núcleo média das manchas da } \\
\text { classe de interesse (em ha). }\end{array}$ & & & \\
\hline $\begin{array}{l}\text { CPLAND (Core Area } \\
\text { Percent of Landscape) }\end{array}$ & $\begin{array}{l}\text { Porcentagem da área-núcleo total da } \\
\text { classe de interesse (em \%). }\end{array}$ & & & \\
\hline $\begin{array}{l}\text { ENN_MN } \quad \text { (Euclidean } \\
\text { Nearest Neighbor } \\
\text { Distance Mean) }\end{array}$ & $\begin{array}{l}\text { Distância euclidiana média de borda- } \\
\text { a-borda entre uma mancha e sua } \\
\text { vizinha mais próxima da mesma } \\
\text { classe }(\mathrm{em} \mathrm{m}) \text {. }\end{array}$ & \multirow{2}{*}{\multicolumn{2}{|c|}{$\begin{array}{lll}\text { Analisar o } & \text { grau } \\
\text { isolamento } & \mathrm{e} \\
\text { conectividade. } & \end{array}$}} & \\
\hline $\begin{array}{l}\text { COHESION } \quad \text { Patch } \\
\text { Cohesion Index })\end{array}$ & $\begin{array}{l}\text { Grau de conectividade da classe na } \\
\text { paisagem }(0<\text { COHESION }<100) \text {. }\end{array}$ & & & \\
\hline
\end{tabular}

Fonte: Adaptado de Metzger (2012).

Para os cálculos das áreas-núcleo das classes de interesse tomou como base Rodrigues (1998), que assinala que o efeito de borda exerce influência sobre características ambientais como, por exemplo, a umidade relativa do ar, temperatura, intensidade luminosa e vento, as quais condicionam o desenvolvimento da vegetação e sua respectiva composição e diversidade de espécies, até uma distância de 35 metros da borda Além disso, levou-se em consideração o fato de que o efeito de borda é espécie-específico e, portanto, não há uma "largura padrão" para a detecção da ação das bordas, ou de outra forma, para a tomada de decisão de onde termina uma borda e se inicia uma área-núcleo (LANG; BLASCHKE, 2009). Dessa forma, como o presente estudo não está analisando nenhuma espécie ou processo específico, foi considerada uma área de amortecimento de 35 m como buffer negativo em direção ao interior dos fragmentos, para a execução do cálculo das métricas que analisam os efeitos de borda, conforme é exigido pelo Fragstats.

O grau de fragmentação florestal foi analisado seguindo a abordagem de Fahrig (2003) através da medição do padrão de habitat em escala de paisagem. Essa medição considera os quatro efeitos provocados pelo processo de fragmentação no padrão do habitat: redução da quantidade de habitat; aumento do número de manchas; diminuição nos tamanhos das manchas e aumento no isolamento das manchas. Para tanto, foram analisados os parâmetros de composição e de disposição da classe Manchas Florestais segundo as métricas: NP; CA; AREA_MN; LPI; SHAPE_MN; TCA; CORE_MN; CPLAND; ENN_MN e; COHESION. 


\section{RESULTADOS}

As duas microbacias abrigavam, na data analisada, 649 fragmentos (NP) distribuídos em seis classes de cobertura e uso da terra (PR), totalizando 4.453,9 ha (TA) (Tabela 1, extraída da Figura 2). 
Tabela 1 - Número de fragmentos (NP), área em ha (AREA) ocupada e percentual de representatividade (\%) de cada classe de cobertura e uso da terra em relação à área total da paisagem das microbacias do rio Carvão e do rio América, município de Urussanga, sul de Santa Catarina.

\begin{tabular}{lccc}
\hline \multicolumn{1}{c}{ Classes } & NP & ÁREA & $(\%)$ \\
\hline Antrópica & 20 & 372,3 & 8,3 \\
Agroecossistemas & 90 & 212,1 & 4,8 \\
Pastagens & 118 & $1.348,7$ & 30,3 \\
Silvicultura & 111 & 493,4 & 11,1 \\
Manchas Florestais & 102 & $2.007,3$ & 45,1 \\
Massas D'água & 208 & 20,1 & 0,4 \\
\hline TOTAIS & $\mathbf{6 4 9}$ & $\mathbf{4 . 4 5 3 , 9}$ & $\mathbf{1 0 0}$ \\
\hline
\end{tabular}

Fonte: organização dos autores

Figura 2 - Mapa de cobertura e uso da terra nas microbacias do rio Carvão e do rio América Carvão, município de Urussanga, sul de Santa Catarina, imageamento em 2011.

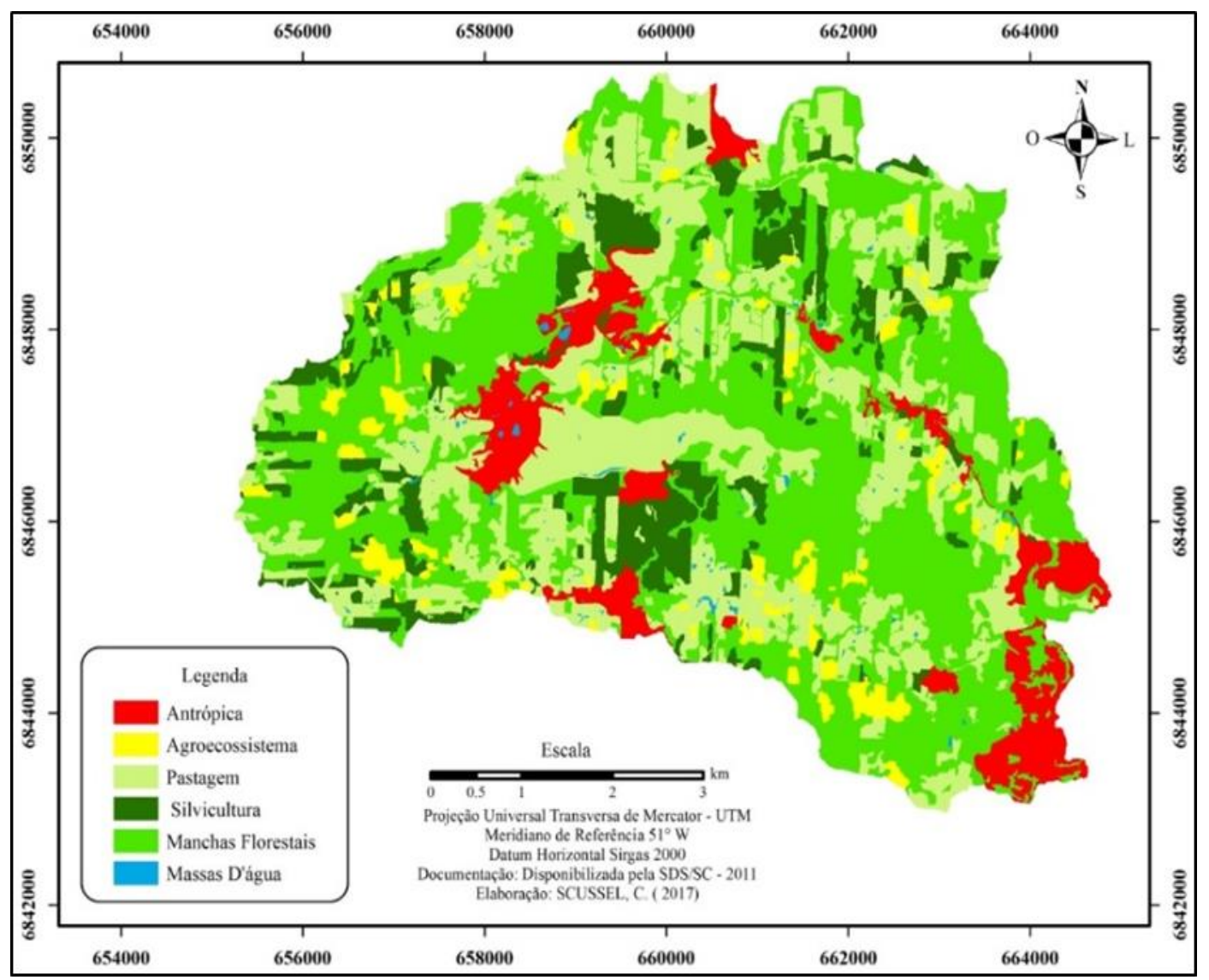

Fonte: organização dos autores 
A paisagem da área analisada caracterizou-se por um mosaico de unidades diferenciadas. As formas de uso da terra predominantes estavam ligadas a atividades antrópicas, as quais em conjunto responderam por mais de $54 \%$ da área mapeada. As manchas florestais integraram a maior quantidade de área na paisagem, ainda que constituídas por vegetação secundária (Tabela 1).

Foram mapeados102 fragmentos. O índice de forma média das manchas florestais foi de 2,2, o que evidencia bordas altamente recortadas, enquanto que a distância média do vizinho mais próximo foi de 45,4 m, o que sugere alto grau de conectividade estrutural entre os remanescentes florestais (Tabela 2).

Tabela 2 - Valores das métricas de disposição utilizadas para analisar a classe Manchas Florestais presente nas microbacias do rio Carvão e do rio América, município de Urussanga, sul de Santa Catarina.

\begin{tabular}{lc}
\hline \multicolumn{1}{c}{ Parâmetros/Métricas } & Valores \\
\hline NP (Número de fragmentos) & 102 \\
AREA (Área total da classe em ha) & $2.007,3$ \\
SHAPE_MN (índice de forma média) & 2,2 \\
SHAPE_MN (das duas maiores manchas) & 12 \\
CORE_MN (área-núcleo média em ha) & 10,7 \\
CPLAND (\% da área total de habitat interior) & 43,5 \\
ENN_MN (distância do vizinho mais próximo em m) & 45,4 \\
COHESION (índice de conectividade entre fragmentos) & 99,9 \\
\hline
\end{tabular}

Fonte: organização dos autores

Dentre os 102 fragmentos, houve predomínio de manchas com área menor do que 6,45 ha (Figura 3). Estes representavam $87 \%$ do total, todavia, ocuparam somente $6 \%$ da área, sendo que 54\% destes foram inferiores a 1 ha (Tabela 3). 
Tabela 3 - Distribuição de frequência dos fragmentos de Manchas Florestais por classe de tamanho presentes nas microbacias do rio Carvão e do rio América situadas no município de Urussanga, sul de Santa Catarina.

\begin{tabular}{|c|c|c|c|c|}
\hline CT (ha) & NP & $\%$ & AREA (ha) & $\%$ \\
\hline$\leq 6,45$ & 89 & 87 & 120 & 6 \\
\hline 6,46|-----| 12,9 & 4 & 4 & 38,2 & 2 \\
\hline 13,00|-----| 19,45 & 2 & 2 & 32,5 & 1,5 \\
\hline $19,46|----| 25,91$ & 1 & 1 & 20,4 & 1 \\
\hline $25,92|----| 32,37$ & 0 & 0 & 0 & 0 \\
\hline 32,38|-----| 38,83 & 1 & 1 & 33,5 & 1,5 \\
\hline $38,84|----| 45,29$ & 2 & 2 & 84,6 & 4 \\
\hline 45,30|----| 51,75 & 1 & 1 & 49,1 & 2,5 \\
\hline 51,76|-----| 440 & 1 & 1 & 438,4 & 22 \\
\hline 440,1|-----| 1191 & 1 & 1 & $1.190,3$ & 59,5 \\
\hline TOTAL & 102 & 100 & $2.007,3$ & 100 \\
\hline
\end{tabular}

Nota: Onde: $\mathrm{CT}$ (ha) = classes de tamanho em hectare ordenadas de acordo com o valor do intervalo $(6,45)$, sendo que para as duas últimas classes foram atribuídos valores diferenciados em função do tamanho dos dois maiores fragmentos serem discrepantes; NP = número de fragmentos para cada classe de tamanho, e seu valor percentual (\%); AREA = Área total em hectares por classe de tamanho, e seu valor percentual (\%).

Fonte: organização dos autores 
Figura 3 - Mapa de distribuição dos fragmentos da classe Manchas Florestais, com destaque aos fragmentos com área $\leq 6,45$ ha (cor preta), na paisagem das microbacias do rio Carvão e do rio América, município de Urussanga, sul de Santa Catarina.

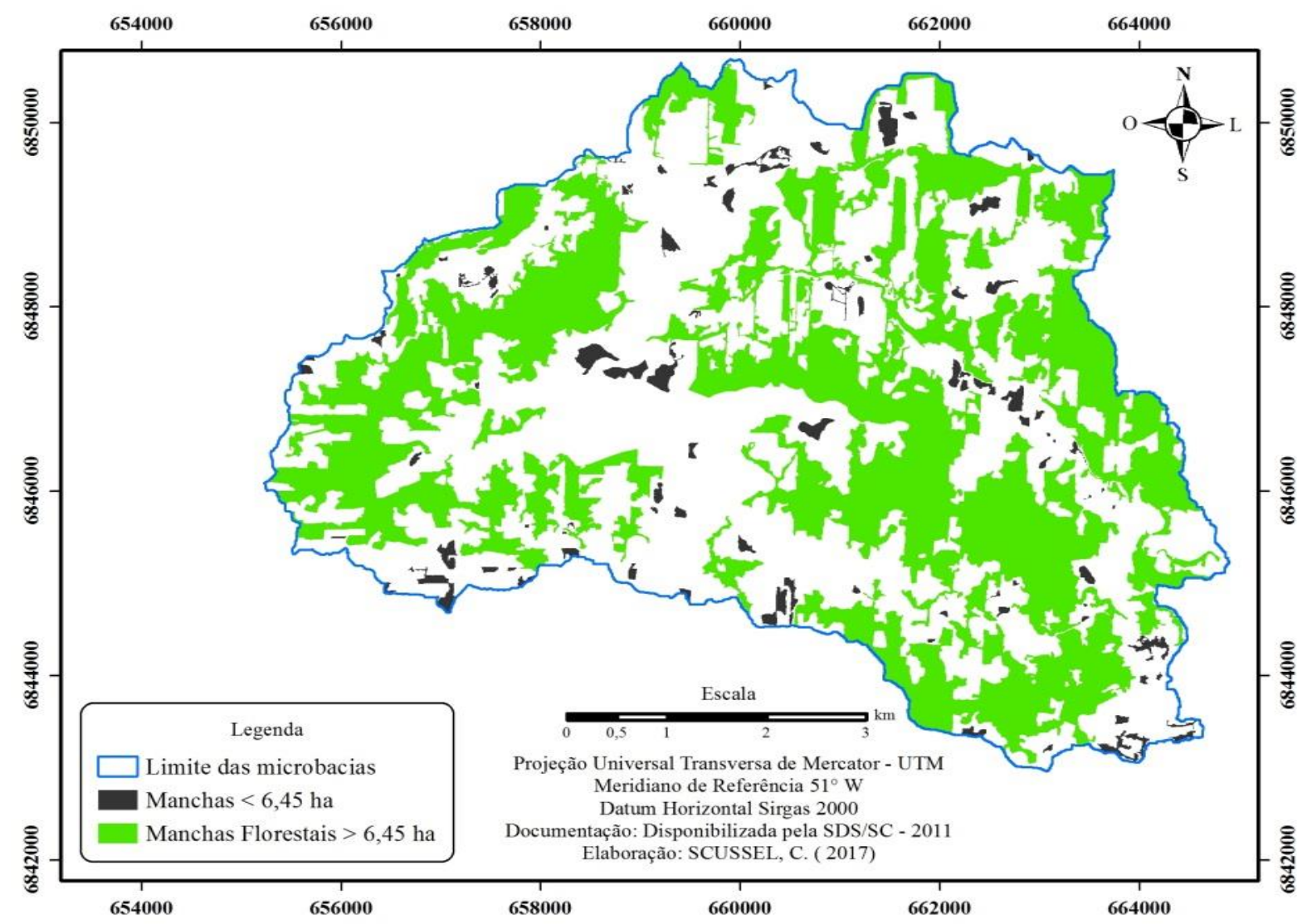

Fonte: organização dos autores

Com a retirada das menores áreas, houve uma redução de aproximadamente $90 \%$ no número de fragmentos. A área total de habitat permaneceu alta em função de os fragmentos menores ocuparem baixa quantidade de área (Tabela 4).

Tabela 4 - Valores das métricas selecionadas para analisar a importância dos menores fragmentos de manchas florestais presentes nas microbacias do rio Carvão e do rio América situadas no município de Urussanga, sul de Santa Catarina.

\begin{tabular}{lccc}
\hline \multirow{2}{*}{ MÉTRICAS } & \multicolumn{3}{c}{ VALORES } \\
\cline { 2 - 4 } & MFT & PF & MFP \\
\hline NP (Número de fragmentos) & 102 & 89 & 13 \\
CA (Área total da classe em ha) & 2007,3 & 120 & 1.887 \\
ENN_MN (Distância do vizinho mais próximo em m) & 45,4 & 197,3 & 76 \\
\hline
\end{tabular}


COHESION (Índice de conectividade entre fragmentos)

99,9

99,3

99,9

Nota: Onde: MFT = manchas florestais - total; PF = pequenos fragmentos e MFP = manchas florestais - parcial (sem os fragmentos $\leq 6,45$ ha).

Fonte: Elaborado pelo autor.

Com a aplicação da borda negativa de 35 m (Figura 7) as áreas-núcleo foram delimitadas, reduzindo a área total da classe para praticamente 50\% (de 2007,3 para 1.085,7 ha), enquanto que a distância do vizinho mais próximo dobrou (de 45,4 m para 81,7 m). 0 índice de conectividade permaneceu inalterado (Tabela 7).

Figura 4 - Mapa temático indicando as áreas-núcleo (em verde) considerando 35 m de borda (em cinza) na paisagem das microbacias do rio Carvão e do rio América, município de Urussanga, sul de Santa Catarina.

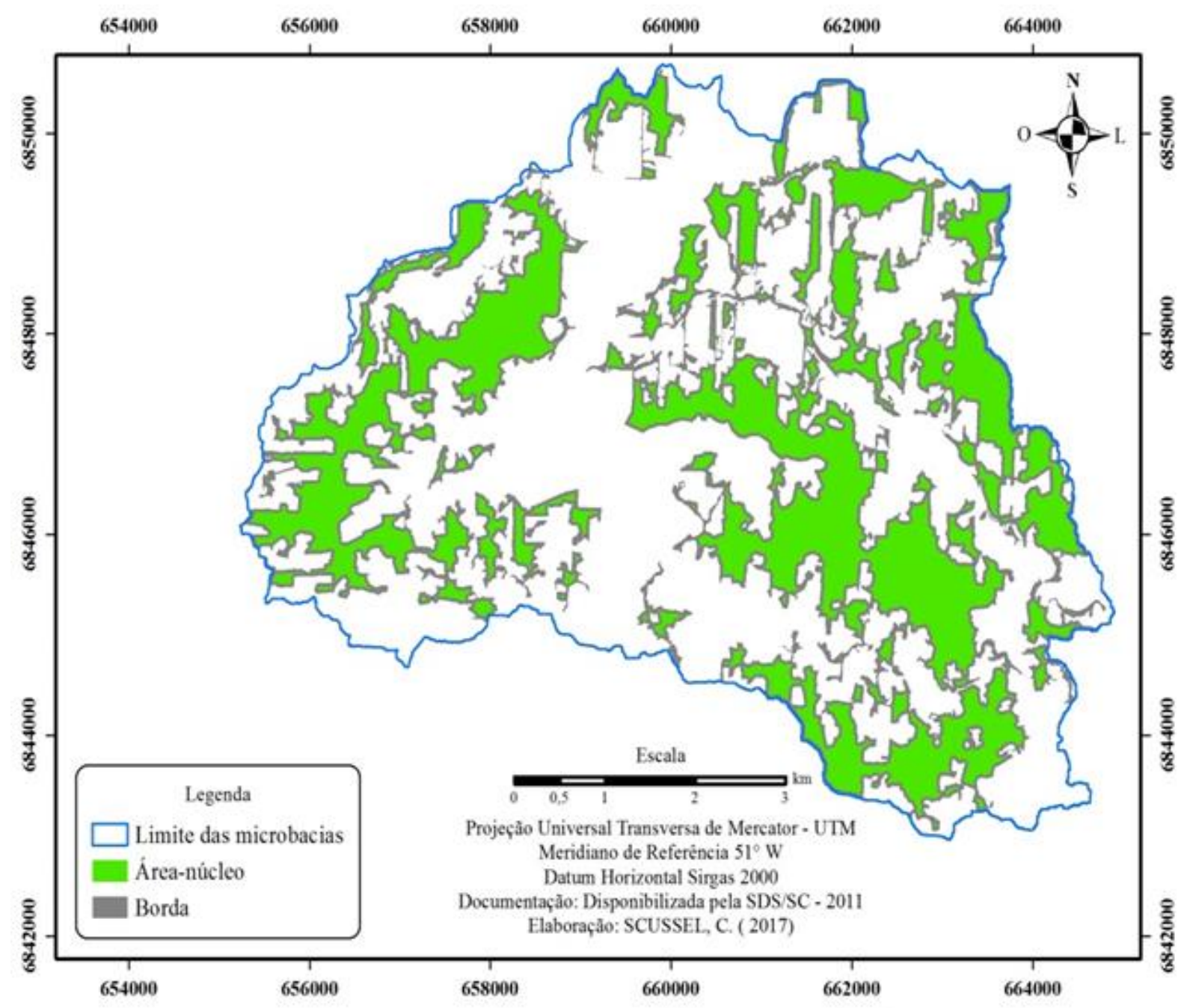

Fonte: organização dos autores 
A simulação infere que 46 \% da área das manchas estão sujeitas aos efeitos de borda e que a área de efetivo habitat não ultrapassa $25 \%$ do total da paisagem, restringindo-se aos fragmentos maiores.

A partir da exclusão das áreas de borda houve diminuição das áreas que podem abrigar espécies dependentes de áreas maiores (TCA: 1.085,7 ha). A explicação está nas formas dos fragmentos que são altamente recortadas e alongadas, tornando algumas manchas até mesmo desprovidas de área-núcleo.

Tabela 5 - Valores das métricas selecionadas para analisar a classe Manchas Florestais em comparação com os valores resultantes depois de retiradas as bordas dos fragmentos de floresta presentes nas microbacias do rio Carvão e do rio América situadas no município de Urussanga, sul de Santa Catarina.

\begin{tabular}{lcc}
\hline \multirow{2}{*}{ MÉTRICAS } & \multicolumn{2}{c}{ VALORES } \\
\cline { 2 - 3 } & HT & HE \\
\hline CA (Área total da classe em ha) & $2.007,3$ & $1.085,7$ \\
ENN_MN (Distância do vizinho mais próximo em m) & 45,4 & 81,7 \\
COHESION (Índice de conectividade entre fragmentos) & 99,9 & 99,9 \\
\hline
\end{tabular}
Nota: Onde: $\mathrm{HT}=$ habitat total e $\mathrm{HE}=$ habitat efetivo.

Fonte: Elaborado pelo autor.

\section{DISCUSSÃO}

Mesmo com o histórico de ocupação antrópica, as áreas florestadas representaram 45,1\% da área total da paisagem estudada. Segundo Andrén (1994) e Fahrig (2003), em se tratando de limiar de fragmentação, o percentual de áreas florestadas sugere que os efeitos poderão estar ligados à perda de habitat uma vez que o resultado está acima dos limites mínimos, entre $20 \%$ e $30 \%$. Paisagens com maior cobertura florestal e com maiores fragmentos se mantêm conservadas e com menor influência da matriz no entorno (SCHAADT; VIBRANS, 2015). Ademais, florestas secundárias propiciam um ambiente 
adequado para várias comunidades viverem, mesmo que não possuam a mesma característica de uma floresta primária (BARLOW, 2007).

A distribuição das manchas florestais se apresentou de forma isolada em decorrência das atividades antrópicas e do número de fragmentos presentes. Esse quadro de fragmentação se repete em praticamente toda a extensão do bioma Mata Atlântica, onde a redução de habitat levou a uma paisagem composta por pequenos fragmentos separados uns dos outros (TABARELLI, 2005). Os resultados corroboram outros estudos na Mata Atlântica, onde também predominaram os menores fragmentos (RIBEIRO, 2009; ABDALLA; CRUZ, 2015; SANTOS, 2017). As florestas secundárias têm essa característica de apresentar muitos fragmentos com tamanhos pequenos (CEMIN; PÉRICO; REMPEL, 2009).

Nossos resultados indicam que as menores áreas de habitat estabelecem importantes conexões entre as duas maiores manchas. É nesse sentido que se esclarece a importância dos menores fragmentos de floresta presentes na paisagem. As inferências acima destacam a relevância das pequenas manchas, pois se forem eliminadas do espaço geográfico que ocupam, pelo fato de serem pequenas, o grau de isolamento aumentará e a conectividade estrutural entre os fragmentos restantes ficará prejudicada. No cenário atual da Mata Atlântica, deve-se considerar cada fragmento como sendo muito importante para a conservação (RIBEIRO, 2009), até mesmo os menores, pois, os maiores já estão protegidos pela legislação ambiental (LAGOS, 2017). O reconhecimento, em escala de paisagem, da importância dos menores fragmentos é uma das estratégias fundamentais para a conservação (NETO; LOYOLA, 2016). Os pequenos fragmentos atualmente estão sendo considerados tão bons quanto os maiores, pois eles têm capacidade de desempenhar papéis ecológicos fundamentais (RESASCO, 2017).

Assim, os pequenos fragmentos podem atuar como stepping stones (trampolins ecológicos) potencializando a permeabilidade da paisagem a partir da conexão que estabelecem entre as áreas-fonte e os demais fragmentos (UEZO; BEYER; METZGER, 2008). Esses trampolins são utilizados principalmente por pássaros que os percebem como possibilidade de parada intermediária (LANG; BLASCHKE, 2009) e por quirópteros (BARROS; BISAGGIO; BORGES, 2006). Ainda, podem manter a biodiversidade local por aumentarem a 
proximidade entre os fragmentos (SOUZA, 2014) e favorecerem a dispersão de propágulos das áreas-fonte.

Mesmo com o alto valor percentual das manchas florestais presente na paisagem estudada (Tabela 2), a quantidade de habitat efetivo disponível para as espécies preocupa. A métrica CORE foi considerada como importante indicativo da qualidade de uma mancha, pois com a redução das áreas de borda ela calcula seu tamanho real (MCGARIGAL; CUSHMAN; ENE, 2012). A simulação realizada inferiu que 46\% da área das manchas estão sujeitas aos efeitos de borda e que a área de efetivo habitat não ultrapassa $25 \%$ do total da paisagem, restringindo-se aos fragmentos maiores. A partir da exclusão das áreas de borda houve diminuição das áreas que podem abrigar espécies dependentes de áreas maiores (TCA: $1.085,7$ ha). A explicação está nas formas dos fragmentos que são altamente recortadas e alongadas, tornando algumas manchas até mesmo desprovidas de área-núcleo.

Grande parte das manchas florestais estudadas estava formada por extensas áreas de borda. Estudos realizados na Mata Atlântica demonstram que as menores manchas florestais sofrem mais as consequências da fragmentação, tanto pelos efeitos de borda (FERNANDES, 2017, LAGOS, 2017) quanto pelos efeitos do isolamento que podem levar os organismos que aí se concentram à extinção (SILVA; SOUZA, 2014), principalmente quando a matriz de contato é antropizada (ETTO, 2013). Nesse sentido, o resultado da métrica ENN_MN $(45,4)$ para a classe indica que as áreas florestadas possuem grau de isolamento estrutural baixo, se considerar a classificação de Almeida (2008), onde a uma distância de 60 m de uma borda a outra o isolamento é considerado baixo; de 120 m é médio; de 200 m é alto e acima deste valor é muito alto.

Fragmentos mais isolados são desvantajosos, principalmente se forem pequenos, sendo mais propícios a eventos de extinções locais (SILVA; SOUZA, 2014). Para Metzger (2012), em longo prazo os fragmentos pequenos só se mantêm se tiver uma fonte estável por perto. O isolamento não depende só da distância, mas também da permeabilidade da matriz, e quanto mais próximos os fragmentos estiverem, torna-se mais fácil de conseguir um repovoamento (LANG; BLASCHKE, 2009).

Os resultados das métricas sugerem que as manchas florestais estavam estruturalmente bem conectadas. Quando os fragmentos possuem alta conectividade, a 
dinâmica de extinção local seguida de recolonização se mantém (METZGER, 2006). Essa condição pode ser favorável para a conservação da biodiversidade principalmente quando enriquecidos por corredores. Entretanto, há espécies que utilizam a matriz como habitat também em algumas paisagens, não havendo uma diferenciação entre "manchas" e "matriz" (FORERO-MEDINA; VIEIRA, 2007).

\section{CONCLUSÕES}

A paisagem das microbacias estudadas se apresentou, a época do estudo, de forma fragmentada devido principalmente ao histórico de ocupação ocorrido desde o século passado. Assim, a paisagem sofreu uma redução na quantidade de habitat florestal efetivo, originou várias manchas pequenas, e se transformou em um mosaico que envolve em maior número atividades de origem antrópica.

As manchas florestais, se distribuíram de forma contígua em maior extensão com as áreas de pastagem. A quantidade de pequenos fragmentos evidenciou ser elevada. Fragmentos de tamanhos menores sofrem com a redução da área central em relação a quantidade de borda, no entanto, funcionam como elo de ligação entre os fragmentos maiores. Estes também possuem forma altamente recortada e alongada, porém, por ocuparem amplamente a paisagem, servem como áreas-fonte.

Embora grande parte da área das duas microbacias estava, à época do estudo, ocupada por formações florestais e a conectividade estrutural fosse elevada, a perda de habitat foi de mais de 50\%, como resultado da ocupação humana desordenada, indicando que as maiores áreas em conjunto com os pequenos fragmentos devem ser motivo de conservação.

Os dados gerados podem subsidiar novas pesquisas, e o cenário apresentado sobre a unidade de pesquisa pode servir de incentivo à criação de medidas de conservação a fim de minimizar os impactos causados sobre os recursos naturais da região necessários à sobrevivência das espécies. 


\section{REFERÊNCIAS BIBLIOGRÁFICAS}

ABDALLA, L. S.; CRUZ, C. B. M. Análise de fragmentação florestal no município de Silva Jardim, APA do rio São João, RJ. Revista Brasileira de Cartografia, v. 1, n. 67, p. 169-184, jan./fev. 2015. ALMEIDA, C. G. Análise espacial dos fragmentos florestais na área do Parque Nacional dos Campos Gerais, Paraná. 2008. 72 f. Dissertação (Mestrado em Gestão do Território) Universidade Estadual de Ponta Grossa, Ponta Grossa, 2008. Disponível em: < http://www.educadores.diaadia.pr.gov.br/arquivos/File/2010/artigos_teses/teses_geografia2008/ds sertacaocristinagalmeida.pdf $>$. Acesso em: 03 mar. 2017.

ALVARES, C. A. Köppen's climate classification map for Brazil. Meteorologische Zeitschrift, vol. 22, n. 6, p. 711-728, 2014.

ANDRÉN, $\mathrm{H}$. Effects of habitat fragmentation on birds and mammals in landscapes with different proportions of suitable habitat: a review. Oikos, v. 71, p. 355-366, 1994.

BARLOW, J. Quantifying the biodiversity value of tropical primary, secondary, and plantation forests. PNAS, v. 104, n. 47, p. 18555-18560, 2007.

BARROS, R. S. M.; BISAGGIO; E. L.; BORGES, R. C. Morcegos (Mammalia, Chiroptera) em fragmentos florestais urbanos no município de Juiz de Fora, Minas Gerais, Brasil. Biota Neotropica, v. 6 , n. 1, 2006.

BELOLLI, M.; QUADROS, J.; GUIDI, A. A história do carvão de Santa Catarina. Criciúma: Impressa Oficial do Estado de Santa Catarina, v. 1, 2002.

CEMIN, G.; PÉRICO, E.; REMPEL, C. Composição e configuração da paisagem da sub-bacia do Arroio Jacaré, Vale do Taquari, RS, com ênfase nas áreas de florestas. Revista Árvore, v. 33, n.4, 2009.

CERQUEIRA, R. Fragmentação: alguns conceitos. In: RAMBALDI, D. M.; OLIVEIRA, D. A. S. (Org.). Fragmentação de Ecossistemas: Causas, efeitos sobre a biodiversidade e recomendações de políticas públicas. Brasília: MMA/SBF, 2003. p. 24-40.

CONSTANTINO, R. Causas da fragmentação: causas naturais. In: RAMBALDI, D. M.; OLIVEIRA, D. A. S. (Org.). Fragmentação de Ecossistemas: Causas, efeitos sobre a biodiversidade e recomendações de políticas públicas. Brasília: MMA/SBF, 2003. p. 43-63.

EMBRAPA. Solos do Estado de Santa Catarina. 46. ed. Rio de Janeiro: EMBRAPA Solos, 2004.

EPAGRI. Dados e Informações Biofísicas da Unidade de Planejamento Regional Litoral Sul Catarinense - UPR 8. Florianópolis: EPAGRI, 2001.

ETTO, T. L. Ecologia da paisagem de remanescentes florestais na Bacia Hidrográfica do Ribeirão das Pedras - Campinas-SP. Revista Árvore, v. 37, n. 6, p. 1063-1071, 2013.

FAHRIG, L. Ecological Responses to Habitat Fragmentation per se. Annual Reviews of Ecology, Evolution and Systematics, 48 (in press), 2017 a.

FAHRIG, L. Effects of habitat fragmentation on biodiversity. Annual Review of Ecology, Evolution and Systematics, n. 34, p. 487-515, 2003.

FAHRIG, L. Issues and perspective in Landscape Ecology, ed. John A. Wiens and Michael R. Moss.

Published by Cambridge University Press, p. 1-10, 2005. Disponível em: <http://glel.carleton.ca/PDF/landPub/05/05Fahriglssues\&Perspectives\%20in\%20LE.pdf> Acesso em: 18 set. 2017. 
FERNANDES, M. Ecologia da Paisagem de uma Bacia Hidrográfica dos Tabuleiros Costeiros do Brasil. Floresta e Ambiente, v. 24, 2017.

FLORENZANO, T. G. Imagens de satélite para estudos ambientais. São Paulo: Oficina de Textos, 2002.

FONSECA, R. C.; DIEHL, E. Riqueza de formigas (Hymenoptera, Formicidae) epigéicas em povoamentos de Eucalyptus spp. (Myrtaceae) de diferentes idades no Rio Grande do Sul, Brasil. Revista Brasileira de Entomologia, v. 48, n. 1, p. 95-100, 2004.

FORERO-MEDINA, G.; VIEIRA, M. V. Conectividade funcional e a importância da interação organismo-paisagem. Oecologia Brasiliensis, v. 11, n. 4, p. 493-502, 2007.

FORMAN, R. T. T. Land Mosaics: The ecology of landscapes and regions. Cambridge: Cambridge University Press, 1995 . Disponível em: < https://books.google.com.br/books/about/Land_Mosaics.html?id=sSRNU_5P5nwC\&redir_esc=y>. Acesso em: 09 dez. 2016.

GABRIEL, V. A. A importância das plantações de eucalipto na conservação da biodiversidade. Pesquisa Florestal Brasileira, v. 33, n. 74, p. 203-213, 2013.

IBGE. Diagnóstico ambiental do litoral de Santa Catarina: caracterização sócio-econômica da zona costeira de Santa Catarina. Florianópolis, 1997.

IBGE. Manual técnico da vegetação brasileira. 2. ed. Rio de Janeiro: IBGE, 2012.

JACKSON, H. B.; FAHRIG, L. Habitat loss and fragmentation. Encyclopedia of Biodiversity, v. 4, p. 50-58, 2013.

LAGOS, M. C. C. Efeito de borda em fragmentos do bioma Cerrado e Mata Atlântica. 2017. 86 f. Tese (Doutorado em Ciências Ambientais). Universidade Federal de Goiás, Goiânia, 2017. Disponível em: <https://repositorio.bc.ufg.br/tede/handle/tede/7610>. Acesso em: 07 dez. 2017.

LANG, S.; BLASCHKE, T. Análise da paisagem com SIG. São Paulo: Oficina de Textos, 2009.

LAURANCE, W. F.; VASCONCELOS, H. L. Consequências ecológicas da fragmentação florestal na Amazônia. Oecologia Brasiliensis, v.13, n. 3, p. 434-451, 2009.

LIMA, I. P. Morcegos (Mammalia; Chiroptera) de áreas nativas e áreas reflorestadas com Araucaria angustifólia, Pinus taeda e Eucalyptus spp. na Klabin - Telâmaco Borba, Paraná, Brasil. 2008. 100 f. Tese (Doutorado em Biologia Animal) - Universidade Federal Rural do Rio de Janeiro, Seropédica, $2008 . \quad$ Disponível em: < www.ufrrj.br/posgrad/cpgba/teses/Tese_Isaac_Passos_de_Lima[1].pdf>. Acesso em: 05 dez. 2017. LINDENMAYER, D. B.; LUCK, G. Synthesis: Thresholds in conservation and management. Biological Conservation, v. 124, p. 351-354, 2005.

LINDENMAYER, D. B.; LUCK, G. Synthesis: Thresholds in conservation and management. Biological Conservation, v. 124, p. 351-354, 2005.

MARCON, L. Análise da expansão urbana de Araranguá, SC e suas implicações ambientais: uma abordagem interdisciplinar. 2014. 92p. Dissertação (Mestrado em Ciências Ambientais). Universidade do Extremo Sul Catarinense, Criciúma, 2014.

MCGARIGAL, K.; CUSHMAN, S. A.; ENE, E. 2012. FRAGSTATS v4: Spatial Pattern Analysis Program for Categorical and Continuous Maps. Computer software program produced by the authors at the University of Massachusetts, Amherst. Disponível em: <http://www.umass.edu/landeco/research/fragstats/fragstats.html>. Acesso em: 03 fev. 2017. 
MCGARIGAL, K.; MARKS, B. J. Fragstats: Spatial Pattern Analysis Program for Quantifying Landscape Structure. U.S. Department of Agriculture, Forest Service, Pacific Northwest Research Station, Portland, USA, v. p. 351, 134, 1995. Disponível em: < http://www.umass.edu/landeco/pubs/mcgarigal.marks.1995.pdf>. Acesso em: 12 dez. 2016.

METZGER, J. P. Como lidar com regras pouco óbvias para consenação da biodiversidade em paisagens fragmentadas. Natureza \& Conservação, v. 4, n. 2, p. 11-23, 2006.

METZGER, J. P. Estrutura da paisagem e fragmentação: análise bibliográfica. Anais da Academia Brasileira de Ciências, v. 71, n. 3, p. 445-463, 1999.

METZGER, J. P. Estrutura da paisagem: o uso adequado de métricas. In: CULLEN, L. Jr; RUDRAN, R.; VALLADARES-PADUA, C. (Org.). Métodos de estudos em Biologia da Conservação e manejo da vida silvestre. Curitiba: UFPR, $2^{\text {a }}$ ed. 2012.

METZGER, J. P. Perda e fragmentação de habitat e biodiversidade. 2013. Disponível em: <http://web01.ib.usp.br/bie314/2013/aula3_Fragmentacao_2013.pdf>. Acesso em: 12 dez. 2016.

MORAES, M. E. B. Análise métrica da paisagem na bacia do rio Água Preta do Mocambo, Uruçuca, sul da Bahia. REDE - Revista Eletrônica do PRODEMA, v. 9, n. 1, p. 62-72, 2015.

NETO, P. L.; LOYOLA, R. Biogeografia da conservação. In: ALMEIDA, E. A. B.; CARVALHO, C. J. B. (Org.). Biogeografia da América do Sul: análise de tempo, espaço e forma. 2. ed. Rio de Janeiro: Roca, 2016, p. 169-178.

OCHOA-QUINTERO, et al. Thresholds of species loss in Amazonian deforestation frontier landscapes. Conservation Biology, v. 29, n. 2, p. 440-451, 2015.

PIAZZA, W. F.; HÜBENER, L. M. Santa Catarina: história da gente. Florianópolis: Lunardelli, 1983.

RESASCO, J. The contribution of theory and experiments to conservation in fragmented landscapes. Ecography, v. 40, p. 109-118, 2017.

RIBEIRO, M. C. The Brazilian Atlantic Forest: How much is left, and how is the remaining forest distributed? Implications for conservation. Biological conservation, v. 142, n. 6, p. 1141-1153, 2009.

ROCHA, J. S. M., KURTZ, S. M. J. M. Manual de Manejo integrado de bacias hidrográficas. Santa Maria/RS: Edições UFSM CCR/UFSM, 2001.

SANTOS, J. F. C. Fragmentação florestal na Mata Atlântica: o caso do município de Paraíba do Sul, RJ, Brasil. Revista Brasileira de Biociências, v. 5, n. 3, p. , 2017.

SCHAADT, S. S.; VIBRANS, A. C. O uso da terra no entorno de fragmentos florestais influencia a sua composição e estrutura. Floresta e Ambiente, Seropédica, v. 22, n. 4, p. 437-445, 2015.

SCHEIBE, L. F.; BUSS, M. D. (Org.); FURTADO, S. M. A. (Org.). Atlas Ambiental da Bacia do Rio Araranguá. 1. ed. Florianópolis: Cidade Futura, 2010. v. 1. 64p.

SILVA, M. S. F.; SOUZA, Rosemeri M. Padrões espaciais de fragmentação florestal na FLONA do Ibura - Sergipe. Mercator, v. 13, n. 3, p. 121-137, 2014.

SOUZA, C. G. Análise da fragmentação florestal da Área de Proteção Ambiental Coqueiral, Coqueiral - MG. Ciência Florestal, v. 24, n. 3, p. 631-644, 2014.

TABARELLI, M. Challenges and opportunities for biodiversity conservation in the Brazilian Atlantic Forest. Conservation Biology, v. 19, n. 3, p. 695-700, 2005. 
TAYLOR, P. D. Connectivity is a vital element of landscape structure. Oikos, v. 68, n. 3, p. 571-573, 1993.

UEZO, A.; BEYER, D. D.; METZGER, J. P. Can agroforest woodlots work as stepping stones for birds in the Atlantic Forest region? Biodiversity and Conservation, v. 17, n. 8, p. 1907-1922, 2008.

VIBRANS, A. C. O inventário florístico florestal de Santa Catarina. In: SEVEGNANI, L.; SCHROEDER, E. (Org.). Biodiversidade catarinense: características, potencialidades e ameaças. Blumenau: Edifurb, 2013, p. 90-91.

WILCOVE, D. S.; MCLELLAN, C. H.; DOBSON, A. P. Habitat fragmentation in the temperate zone. Conservation Biology, v. 6, p. 237-256, 1986. 